\title{
A pesquisa em educação no Brasil
}

\author{
Elizabeth Macedo
}

Universidade do Estado do Rio de Janeiro, Programa de Pós-Graduação em Educação

\section{Clarilza Prado de Sousa}

Pontifícia Universidade Católica de São Paulo, Programa de Pós-Graduação em Educação

\section{Introdução}

Inicialmente, julgamos necessário explicitar o estranho lugar de onde falamos. Nossa familiaridade com a temática se dá na medida em que somos partícipes de um sistema de pós-graduação e de pesquisa em seus múltiplos espaços, e não estudiosas do tema. Nesse momento, essa participação envolve a posição de representantes da área junto à Coordenação de Aperfeiçoamento do Pessoal de Nível Superior (CAPES) e, portanto, a tarefa de conduzir o processo de avaliação dos programas no triênio 2007-2009. Se é discutível a possibilidade mesma da representação - já que o ato de representar envolve a incorporação do representado à esfera política com uma identidade criada pela interpelação do representante àqueles que ele representa (Laclau, 1993)-, seu exercício em uma exposição como esta é ainda mais inusitado. No âmbito de nossa ação prática, podemos buscar agir como representantes, certas da incompletude do ato de representar, que é simultaneamente sua condição de possibilidade e impossibilidade.

Num espaço teórico como este, estamos num terreno movediço. Por sua natureza acadêmica, nossa exposição não pode prescindir de análise, o que não pode ser feito desse lugar de representantes. Ao mesmo tempo, seria naive acreditar que podemos fazê-lo de outro lugar, desde que explicitemos essa desvinculação. É, portanto, nesse espaço ambíguo que construímos este texto em que pretendemos discutir aspectos da política de pós-graduação (em educação), entendendo-a como diretamente relacionada à política de pesquisa. Em áreas como a educação, praticamente toda pesquisa é desenvolvida nos programas de pós-graduação ou por sujeitos formados para a pesquisa nesses programas.

Dito isso, assumimos nossa rejeição à ideia de que existiria um modelo ideal de política para a pósgraduação, postura que, a nosso ver, viabiliza visões nostálgicas. Autores como Cameron e Gatewood (1994) têm tratado a nostalgia como uma adaptação psicológica às frenéticas mudanças que experimentamos no campo da cultura, de modo que ela pode ser sentida até por aqueles entre nós que não vivemos aquilo que recordamos. Trata-se de algo que se processa tanto no âmbito individual quanto coletivo, refletindo o que se quer lembrar, mas também aquilo que se busca esquecer. Se a nostalgia pode ser reflexiva (Boym, 2001), 
permitindo o pensar sobre a história e a passagem do tempo, ela também pode assumir contornos restaurativos, celebrando romanticamente um passado vivido apenas como fantasia presente. $\mathrm{O}$ perigo da nostalgia restaurativa é maquiar a própria nostalgia, apresentada como uma tentativa de recuperar algo tido como verdade absoluta.

Nossa postura está longe de uma nostalgia restaurativa. Entendemos que a pós-graduação e a pesquisa na área de educação, ao longo dos últimos trinta anos, viveu intensa consolidação, que pode ser percebida, entre outros fatores, pela ampliação das demandas por financiamento em diferentes agências. Trata-se de uma trajetória comum a outras áreas das ciências sociais e das humanidades que, como ressalta Velho (1997), por vezes faz parecer desestruturação, o que é uma "saudável vitalidade da comunidade" científica na competição por recursos que não foram ampliados na mesma medida em que aumentaram as demandas. Segundo esse autor (idem, p. 5), a maior institucionalização do sistema provocou algum desconforto pela maior competitividade por recursos, mas foi "absolutamente crucial para que a pesquisa propriamente dita desse um salto" e as áreas consolidassem-se.

Ao mesmo tempo em que reconhecemos enormes avanços da pós-graduação em geral e da área de educação em particular, corroboramos algumas críticas à política de pós-graduação que vêm sendo apresentadas em diferentes análises (Horta, 2002; Horta \& Moraes, 2005; Kuenzer \& Moraes, 2005; Sguissardi, 2006; Fávero, 2009). Consideramos, no entanto, que a maioria delas opera com um modelo de política em que as principais ações são localizadas no espaço do Estado, tratando as esferas não governamentais apenas como reativas. Assim, as ações do Estado são criticadas e, mesmo quando o conceito de Estado assume uma perspectiva gramsciana de Estado ampliado, a independência material relativa entre sociedade política e sociedade civil é negligenciada (Lopes, 2006). Ainda assim, vemos nesses trabalhos importante contribuição para pensar a pós-graduação, especialmente em função de serem construídos a partir de um mosaico de vivências de seus autores nesse sistema. Permitem- nos, portanto, acompanhar um pouco mais de perto o cotidiano dessa discussão em espaços-tempos de que não participamos.

Alternativamente, temos entendido (em estudos do campo do currículo) que a saturação total dos espaços cotidianos é impossível, não importa quão intensos sejam os mecanismos de controle impostos por globalismos econômicos e autoritarismos políticos (Hall, 2003). Esse entendimento não implica desvalorizar o Estado como constituinte das políticas, assumindo posturas relativistas, mas entendê-lo como uma articulação, entre várias, de discursos que lutam por espaço (Laclau \& Mouffe, 2004). Aqui tomamos discurso numa perspectiva pós-estrutural como fenômenos não apenas linguísticos, que se articulam com instituições, práticas econômicas, políticas e culturais, assim como com procedimentos normativos que constituem o social. Nesse sentido, quando falamos de uma política de pósgraduação, estamo-nos referindo a diferentes discursos circulantes que se tornam hegemônicos e se universalizam provisoriamente, reestruturando nossa forma de compreender o social (Laclau \& Mouffe, 2004). Os "autores" desses discursos somos todos nós - e também eles - nos espaços em que produzimos sentidos sobre o que vem a ser a pós-graduação de qualidade.

Tomando a política de pós-graduação como politização incessante, sempre habitada pela indecidibilidade, tentaremos analisar alguns consensos que "se manifestam como a estabilização de algo essencialmente não estável e caótico" (Mouffe, 2003, p. 147). Para tanto, tomaremos para análise alguns textos em que esses consensos provisórios em torno de posições hegemônicas são explicitados. Nossa crença é de que é possível, por meio da análise dos textos de política, compreender a formação provisória de consensos em torno de noções como a qualidade da pós-graduação, entendida como significante vazio preenchido por meio de articulações hegemônicas.

O recorte dos textos com os quais vamos trabalhar é marcado por nossa condição de participantes do sistema de pós-graduação que, nos últimos anos, estiveram ligadas aos processos de avaliação coordenados pela CAPES. Para as considerações que teceremos sobre a 
política de pós-graduação em educação no país, optamos por nos basear nos documentos produzidos pela avaliação: fichas, pareceres e resultados da avaliação, assim como em documentos de área. Entendemos que eles expressam determinadas posições sobre o que é qualidade da pós-graduação tornadas hegemônicas em determinados momentos.

Mesmo reduzindo o número de documentos passíveis de análise, ainda temos necessidade de focar apenas alguns aspectos, como forma de dar conta da tarefa de falar da pesquisa em educação a partir da análise da política de pós-graduação. Após traçar um quadro muito geral do sistema, vamo-nos fixar em dois pontos que nos parecem centrais nessa política e que se referem diretamente à temática da pesquisa. $\mathrm{O}$ primeiro, de natureza processual, diz respeito à organização dos programas em núcleos que dão centralidade à pesquisa. O segundo é um indicador de resultados que vem sendo apontado, por muitos de nós, como o principal indicador da avaliação: a produção bibliográfica dos programas.

\section{O sistema de pós-graduação em educação}

Inicialmente, selecionamos dados que nos permitem perceber como se encontra o sistema de pósgraduação em educação no país. Desde o início da pós-graduação em educação, em 1965, o crescimento do número de mestrados e doutorados tem sido constante, com alguns momentos de maior gradiente de expansão (Gráfico 1).

Gráfico 1: Crescimento do número de cursos de pósgraduação por ano 1965-2008

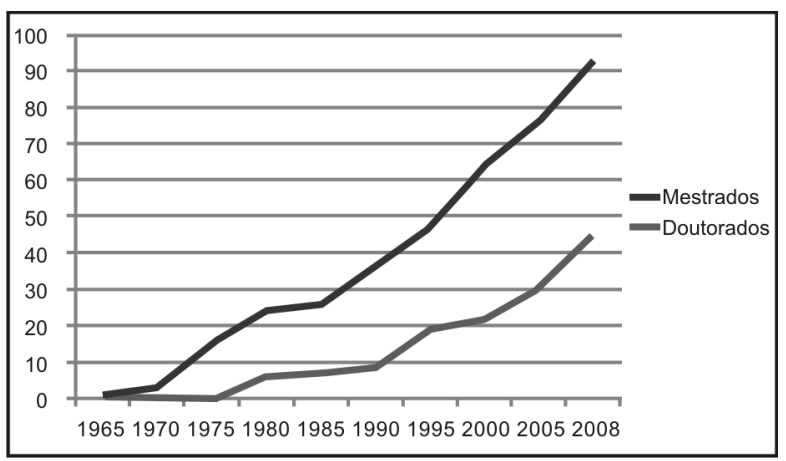

Esse crescimento tem sido mais sentido atualmente em instituições estaduais e particulares (Gráfico 2). Ainda que essa distribuição se tenha concentrado em determinadas regiões geográficas, optamos por não discutir tal fato por entender que, como não podemos realizar nos limites deste texto uma análise consistente cruzando diferentes indicadores, a pura e simples apresentação da distribuição serviria apenas para consolidar estereótipos. Como vem ocorrendo desde 1965, a produção de dissertações e teses cresceu ao longo do último triênio. A maior parte dela ainda se dá em instituições federais, especialmente no que concerne aos cursos de doutorado. Como era de esperar, em virtude de se tratar de cursos recentes, a produção das instituições particulares concentra-se em nível de mestrado (Gráficos 3 e 4).

Gráfico 2: Distribuição de programas por tipo de instituição (2004-2006)

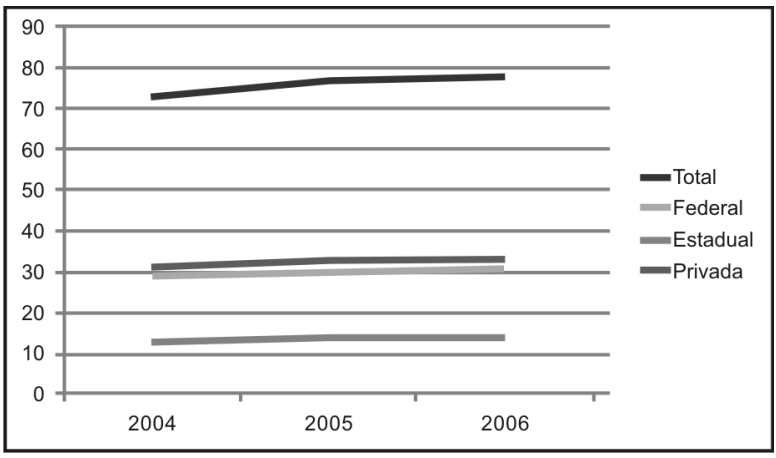

Gráfico 3: Número de titulações em mestrado acadêmico 2004-2006

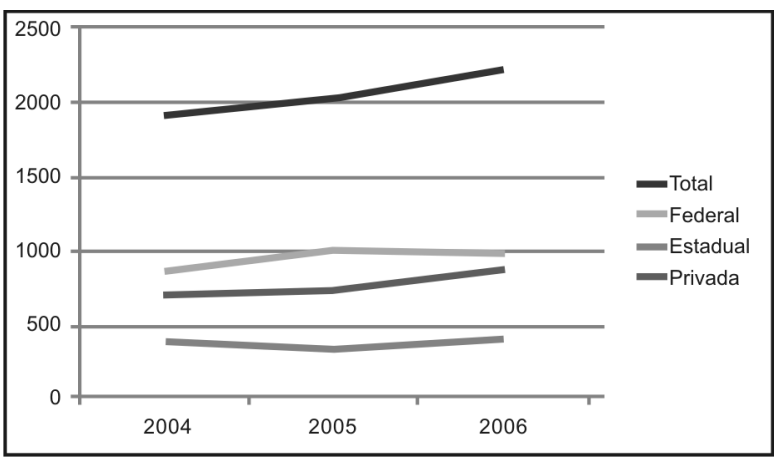


Gráfico 4: Número de titulações em doutorado (2004-2006)

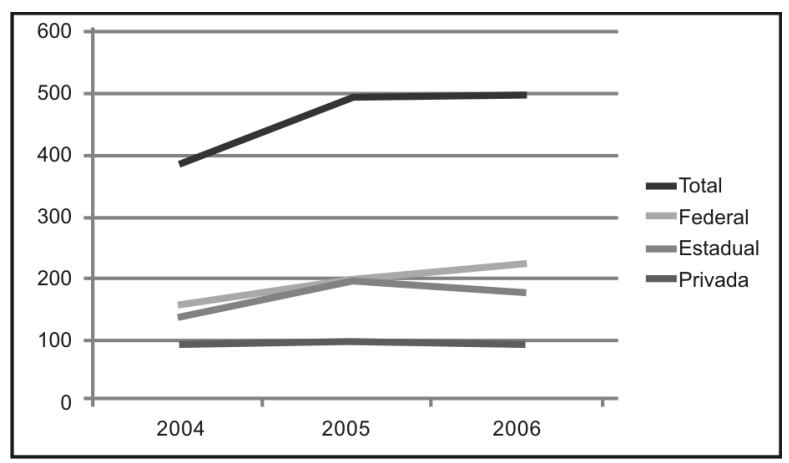

Quanto ao tamanho dos programas, a ampla maioria do sistema é composta por programas de até 30 docentes, sendo $28 \%$ de programas muito pequenos - de até 15 docentes (Gráficos 5 e 6). Como expresso no Gráfico 7, esses programas ocupam, em geral, os estratos mais baixos da avaliação, com conceitos 3 e 4 . Os programas que têm entre 16 e 30 docentes são maioria nos conceitos 4 e 5 . Os programas com mais de 31 docentes concentramse nos conceitos 4 e 5 . Os poucos programas com mais de 50 docentes ocupam os estratos mais elevados da avaliação. Os programas 5 e 6 tendem a ser maiores: no caso dos 6 , mesmo os oferecidos por instituições privadas têm mais de 16 docentes. Trata-se de números que indicam que os resultados da avaliação estão, no geral, refletindo a consolidação dos programas.

Gráfico 5: Número de docentes por programa e tipo de instituição (2004-2006)

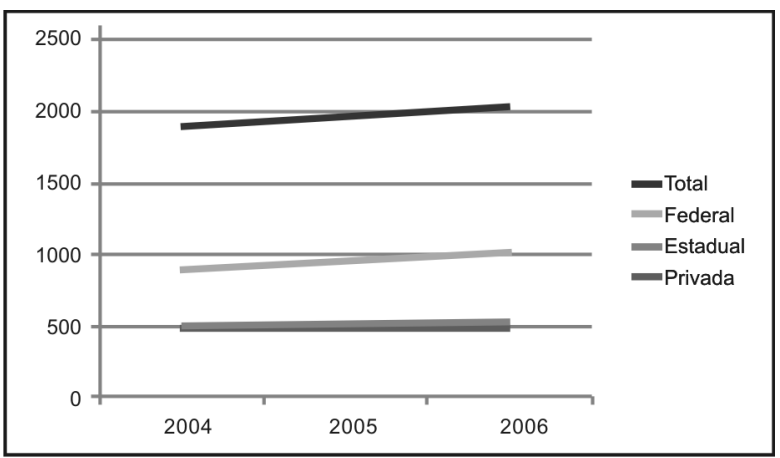

Gráfico 6: Número de docentes por programa

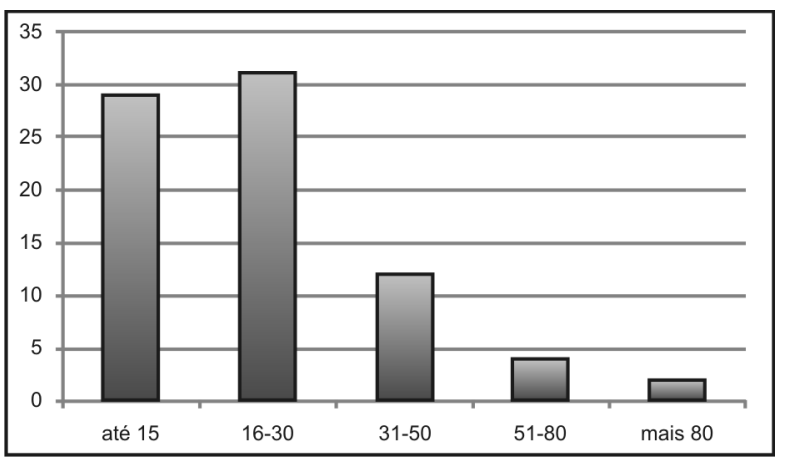

Gráfico 7: Dimensão do corpo docente por nota do programa

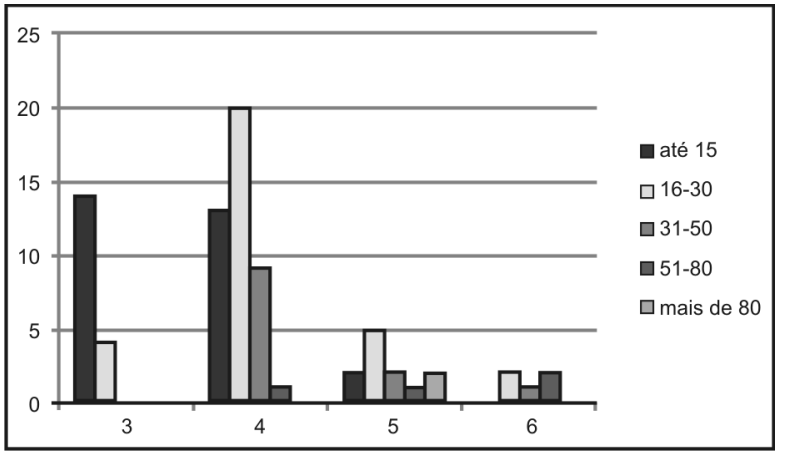

Do ponto de vista da ampliação do sistema de pós-graduação, parece que estamos atingindo certa saturação. A capacidade de criação de novos cursos de mestrado vem-se reduzindo e concentrando-se em universidades privadas. No nível de doutorado, ainda há algum fôlego, mas em geral os cursos novos contam com reduzido número de docentes, o que deve dificultar-lhes atingir níveis de excelência. Parece estarmos num momento em que é fundamental projetar estratégias para a continuidade da ampliação quantitativa e qualitativa da área. Pensar em associações é talvez uma forma de garantir o crescimento do sistema sem perda da qualidade, facilitando a consolidação de novos programas que venham a atender a enorme demanda por formação pós-graduada stricto sensu na área da educação. 


\section{A formação}

O sistema de pós-graduação brasileiro, iniciado em 1965 a partir do parecer n. 977/65 do Conselho Federal de Educação, viveu rápida expansão como parte de um projeto de Estado que considerava o desenvolvimento científico "pré-condição para o desenvolvimento econômico" (Brasil, 1983, p. 7). Segundo Córdova, Gusso e Luna (1986), a forma desordenada como se expandiu o sistema de pós-graduação fez com que cada curso valorizasse uma das funções que se entendia ter a pós-graduação: formar professores para o ensino superior, capacitar técnicos para operar os projetos governamentais e produzir conhecimentos visando ao desenvolvimento econômico do país. Paradoxalmente, ao mesmo tempo em que os cursos tinham perfis diferenciados devido a essas funções, os currículos assumiram grande homogeneidade. Os cursos organizavam-se em torno de áreas de concentração e de um conjunto de disciplinas obrigatórias de domínio conexo e eletivas, sem grande valorização da pesquisa, tanto docente quanto como atividade orgânica dos programas. Para Fávero (1996), as recomendações dos pareceres n. 977/65 e n. 77/69, embora não obrigatórias, foram seguidas à risca pelos cursos, na medida em que era a partir delas que seu funcionamento era autorizado, condição fundamental para a validação dos certificados e para pleitear financiamento junto aos órgãos estatais.

Especialmente a partir da segunda metade dos anos 1980, o sistema reestruturou-se tomando por base uma série de questionamentos, num momento que Fávero (2009) definiu como de "intensa mobilização". O principal consenso que reorganizaria todo o sistema estabeleceu-se em torno dos objetivos da pós-graduação, com a valorização da formação do pesquisador em detrimento das demais funções até então desempenhadas pelos cursos. Em face dessa alteração, as áreas de concentração, de perfil nitidamente profissional, sofreram críticas de cunho epistemológico, que apontavam para um currículo mais integrado e relacionado à pesquisa. A superação da ideia de área de concentração estava, no entanto, longe de ser unânime. Cunha (1985), por exemplo, explicitava temor de que a extinção ou o alargamento das áreas de concentração prejudicasse a criação de uma identidade para a educação. Em texto datado de 1996, Fávero defendia os núcleos de pesquisa, que enfatizassem a problematização capaz de construir e organizar o conhecimento, em detrimento das áreas de concentração, que supunham a divisão do conhecimento em áreas cujos conteúdos poderiam ser previamente estruturados para serem transmitidos. Em texto mais recente (Fávero, 2009), o autor define como palavras-chave desse processo a flexibilidade, a integração ensino-pesquisa e a interdisciplinaridade. As áreas de concentração parecem totalmente superadas na organização dos programas de pós-graduação. Muitos deles apresentam como área apenas educação, enquanto outros definem um escopo mais restrito, sem, no entanto, cair em campos profissionais comuns no período inicial de consolidação do sistema. Se a ideia de núcleos ou eixos de pesquisa subsiste apenas em uns poucos cursos, a organização por linhas de pesquisa atinge praticamente todos os programas. Fávero (idem) critica o privilégio absoluto da ideia de linhas, entendendo que elas se hegemonizaram em função da pressão do modelo de avaliação utilizado pela CAPES a partir do biênio 1996-1997, com reflexos na avaliação realizada em 1998. Concordamos que a exigência de nucleação em linhas de pesquisa que articulavam uma temática foi problemática para muitos cursos e favoreceu, naquele momento, cursos menores e mais recentes. Entendemos, no entanto, que o que temos hoje em termos de organização é um modelo mais flexível, que, de alguma forma, retoma as ideias de interdisciplinaridade, flexibilidade e integração ensino-pesquisa, produto de uma redefinição da área sobre os sentidos da ideia de linhas de pesquisa.

Horta e Moraes (2005, p. 95), narrando os movimentos ocorridos no Comitê Técnico-Científico da CAPES (CTC/CAPES), nos triênios 1998-2000 e 2001-2003, com destaque para as discussões sobre os níveis de excelência, salientam a desejável "organicidade entre linhas de pesquisa, projetos, estrutura curricular, publicações, teses e dissertações". Concluem que esse modelo, juntamente com a ênfase na produção 
bibliográfica, define a pós-graduação como "locus da produção do conhecimento e da formação de pesquisadores" (idem, ibidem). Diferentemente do que ocorre com outros aspectos do modelo de avaliação, essa ideia de organicidade não é criticada pelos autores. Os documentos da área da educação desde 1998, assim como os instrumentos de avaliação, assumem a positividade dessa articulação tanto para os programas em funcionamento quanto para os cursos novos. O documento do triênio 1998-2000, embora não explicite nos perfis de cada conceito indicador de processo, assegura na ficha de avaliação a importância da consistência da proposta e da articulação das linhas em torno dessa proposta. No triênio 2001-2003, a positividade das linhas de pesquisa torna-se mais explícita, quando a abrangência delas como forma de facilitar a inclusão dos projetos de pesquisa é criticada, na medida em que "de forma alguma assegura a organicidade da proposta" (Brasil, 2004, p. 3). A questão é considerada ainda mais grave na medida em que "as temáticas de teses e, sobretudo, dissertações, guardam pouca ou nenhuma relação com os projetos e mesmo com as linhas" (idem, ibidem). Essa tendência de valorização da organicidade em torno de linhas continua nos documentos de avaliação do triênio seguinte.

A leitura de pareceres encaminhados aos programas ao longo dos três últimos triênios, no entanto, permite perceber que há disputa em torno do entendimento da ideia de organicidade e, mais ainda, da interferência que a avaliação pode ter nas formas de organização dos currículos dos programas. Como movimento geral, é possível dizer que se tem ampliado a visão de que a avaliação deve respeitar a organização proposta pelo programa, exigindo apenas algum nível de integração entre os diferentes elementos curriculares. Em relação à primeira avaliação que usava a ideia de linha de pesquisa, observa-se também maior flexibilidade, de modo que se entenda que a articulação é facilitada em programas menores, mais novos e de instituições particulares. No último triênio de avaliação, por exemplo, a ampla maioria das avaliações dos programas dá conta da organicidade das propostas e da relação no mínimo boa entre linhas e projetos de pesquisa, teses e dissertações, espelhando resultado diferente daquele relatado no documento de área de 2001-2003. Se essa observação pode indicar que a ideia de linhas se consolidou, pode também marcar uma flexibilização do que tem sido entendido por organicidade.

Aceitando a premissa de maior flexibilidade da ideia de linhas de pesquisa em relação ao entendimento a que Fávero (2009) faz menção, julgamos lícito supor que o sentido que vem sendo dado à linha de pesquisa é o de elemento estruturador dos programas em torno da pesquisa. A ideia inicialmente imposta de linhas de pesquisa pode estar-se redefinindo (ou vir a ser redefinida), tendo por base os consensos construídos pela área nos últimos - pelo menos - vinte anos. Nesse sentido, a organização da ampla maioria dos programas em linhas não seria negativa, na medida em que a compreensão das linhas seja alargada e não implique modelo a ser seguido por todos, mas um significante que pode ser diferentemente preenchido pelos programas em função de suas histórias.

Vistas nesse sentido, as linhas podem ser entendidas como uma expressão da forma como os programas estão pensando o próprio campo da educação, num exercício de articulação que tem envolvido interdisciplinaridade e flexibilidade. A partir da descrição das linhas, fizemos um primeiro exercício de compreender a pesquisa na área (há muitos outros dados que poderiam permitir uma análise mais aprofundada, mas não tivemos possibilidade de trabalhar para este artigo). Optamos por um duplo exercício: criamos homogeneidades, ressaltando as temáticas mais e menos recorrentes, ao mesmo tempo em que tentamos perceber a criatividade observada na constituição das linhas, associando temáticas. Sem desconsiderar a possibilidade de que tal associação vise à criação de guarda-chuvas, queremos vê-la em sua dimensão positiva como expressão de uma área que se reinventa.

Em nosso primeiro movimento em busca de regularidades, temas como política e gestão da educação (41), formação e trabalho docente (39), história da educação (27), didática e processos de ensino (22), aprendizagem e desenvolvimento (21) e currículo 
(20) são os mais presentes. Num segundo conjunto aparecem temáticas como ensino de matemática e ciências (17), movimentos sociais (13), linguagem (12), educação especial (12), educação e cultura (12), educação/escola e sociedade (11), educação e trabalho (10), filosofia da educação (9), educação e tecnologia (8) e educação ambiental (8). Alguns temas menos recorrentes são: fundamentos da educação, avaliação, alfabetização, infância, ensino superior, ensino de artes, teoria da complexidade, corpo, educação agrícola, educação e saúde. No geral, as organizações fazem-se com o privilégio de temáticas, em detrimento de campos disciplinares. $\mathrm{O}$ amplo privilégio de áreas como política educacional, história da educação e didática/ currículo/formação de professores indicaria um tripé central dos estudos do campo da educação, o qual não impede o surgimento de temas mais específicos que não se diluem em áreas mais gerais.

Nosso segundo movimento pretendeu perceber a diversidade dentro dessas temáticas aparentemente "clássicas" do campo. Os estudos autonomeados como políticas ou gestão da educação lidam preferencialmente com gestão (20) e políticas públicas (12), embora incluam interfaces com temáticas como práticas, cultura e organização da instituição escolar (11). A vinculação mais explícita entre política e Estado é realizada em apenas três linhas. As linhas de história da educação, em que a historiografia e a teoria da história ocupam posição de relevo (10), são igualmente concentradas em torno de um núcleo central. No entanto, o restante das linhas agrupadas em torno da história mostra ampliação das articulações que indicam uma abordagem histórica de diferentes fenômenos: política educacional (8), filosofia da educação (3), instituições educacionais (3), sociedade (3), cultura (3). Também as linhas sobre a temática aprendizagem e desenvolvimento têm foco central na abordagem psicológica desses processos, mas incluem articulações com ética, valores e, principalmente, constituição do sujeito e da subjetividade nos processos educativos.

É nas linhas sobre temáticas como didática, currículo e formação de professores que se percebe maior interseção. No caso da didática, têm destaque a prática e a sala de aula, a produção e a apropriação de conhecimento/saberes, as disciplinas/interdisciplinaridade, as instituições educacionais, a formação docente. No campo do currículo, a menção à cultura e ao cotidiano da escola é mais frequente (8), mas há um conjunto de outras articulações: avaliação, política, formação de professores, conhecimento. Em relação à formação docente, temas como práticas educativas, identidade, universidade, política e cultura juntam-se às discussões sobre profissionalização e trabalho docente.

Em relação às demais linhas, temáticas como educação especial, trabalho e educação, ensino de matemática e ciências e educação e linguagem são mais homogêneas em relação aos enfoques, enquanto as linhas que dão centralidade à sociedade e à cultura tendem a apontar novas áreas temáticas interdisciplinares.

Esse primeiro esboço permite perceber as áreas privilegiadas na formação em nível de mestrado e doutorado e as áreas que concentram maior parte da pesquisa realizada na pós-graduação. Se não traz grandes surpresas em relação às temáticas privilegiadas na área, indicam também que não há nenhuma articulação forçada apenas como forma de atender aos requisitos ditados pela avaliação.

\section{A produção de conhecimento}

O segundo aspecto que destacaremos é a produção bibliográfica do corpo docente dos programas; com as informações sobre titulação e produção discente, esse ponto forma o tripé de indicadores de produto cada vez mais valorizado na avaliação. As críticas ao modelo de avaliação sustentado por esse tripé são numerosas (Sguissardi, 2006; Horta \& Moraes, 2005; Kuenzer \& Moraes, 2005) e, como já destacamos, concordamos com boa parte das análises. Não há dúvida de que toda a avaliação não pode resumir-se a indicadores quanti-qualitativos de produção bibliográfica, assim como de que indicadores de formação são relevantes e precisam continuar a ser utilizados. Mais do que isso, é inegável a necessidade de uma ação política mais consistente voltada para os usos da avaliação 
no financiamento do sistema de pós-graduação. Há que se discutir mais amplamente se a maioria das linhas de financiamento devem privilegiar a excelência. Tais discussões, a nosso ver, não impedem que concordemos com Kuenzer e Moraes (2005), quando afirmam que o efeito indutor do Estado na transição da centralidade na docência para a pesquisa foi positivo para a pós-graduação. Nesse modelo de pós-graduação voltada para a pesquisa, entendemos que a produção bibliográfica ganha importância e se justifica como indicador de avaliação.

Tendo explicitado nossa posição, gostaríamos de, para desconstruí-las, dialogar com duas afirmativas que vêm sendo assumidas como verdadeiras em algumas de nossas discussões. A primeira sobre a importância do indicador produção bibliográfica na avaliação. Expressamos essa posição com uma citação de Horta (2002), o qual, ao analisar resultados da avaliação de diferentes áreas para o triênio 1998-2000, concluiu que foi a produção bibliográfica o indicador que permitiu aos programas atingir os estratos mais elevados. A segunda relaciona-se ao que temos chamado de produtivismo. No mesmo texto em que reconhecem a positividade de uma pós-graduação centrada na pesquisa, Kuenzer e Moraes (2005, p. 1.349) afirmam que há "um verdadeiro surto produtivista em que o que conta é publicar, não importa qual versão requentada de um produto ou várias versões maquiadas de um produto novo. A quantidade institui-se em meta".

Trabalhando com dados produzidos pelas avaliações, pouco ainda se pode falar sobre a qualidade das produções. A tentativa de qualificação vem sendo feita por meio do que, no âmbito da CAPES, ficou conhecido como Qualis. Em relação aos periódicos, a estratificação de veículos encontra-se mais adiantada, ainda que seja questionável que a avaliação de uma revista seja transportada para todos os seus artigos. No que concerne aos livros, os dados de que dispomos consideram ainda indicadores muito indiretos de qualidade - como a circulação e a gestão editorial -, medidos por uma qualificação de editoras. Considerando esses limites, no entanto, julgamos que uma análise dos dados de produção dos programas gerados para a avaliação trienal 2004-2006 permite questionar afirmativas como a de que existe produtivismo na área ou de que a produção docente tem definido o resultado da avaliação dos programas.

As médias de produção docente por conceito dos programas indicam que há correlação entre a avaliação final dos programas de pós-graduação e a média de produção docente (Gráfico 8). No entanto, há grande variação das médias de produção docente em programas com um mesmo conceito. Com exceção dos programas com conceito 6 , as faixas de média de produção de um conceito interpenetram-se com as dos conceitos superiores. Isso mostra que outros indicadores estão sendo considerados para compor o resultado da avaliação e, a nosso ver, desautorizam a afirmativa de que a produção bibliográfica é a base do modelo que vem sendo utilizado para a avaliação.

Gráfico 8: Mediana da média da produção docente por ano por conceito do programa (calculada em relação a capítulos A)

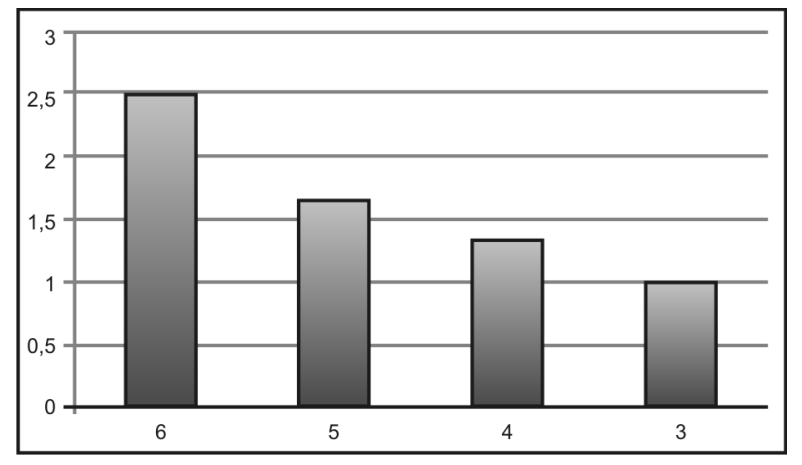

Quanto ao produtivismo, as médias de produção docente por programa (equivalentes a capítulos A) também não indicam excesso de produção. Apenas nos programas 6 (Gráfico 12) observamos média anual de mais de dois produtos (equivalentes a capítulo A) por docente por ano. Dos conceitos 3 a 5, essa média varia de 1 a 1,6 produto (equivalente a capítulo A) (Gráfi$\cos 9$ a 11). Poder-se-ia argumentar que o número de produtos é muito superior, se considerados os valores 
brutos; no entanto, a média em número de produtos é pouco superior aos valores tabelados.

Gráfico 9: Média da produção docente (equivalentes a capítulos A) dos programas 3

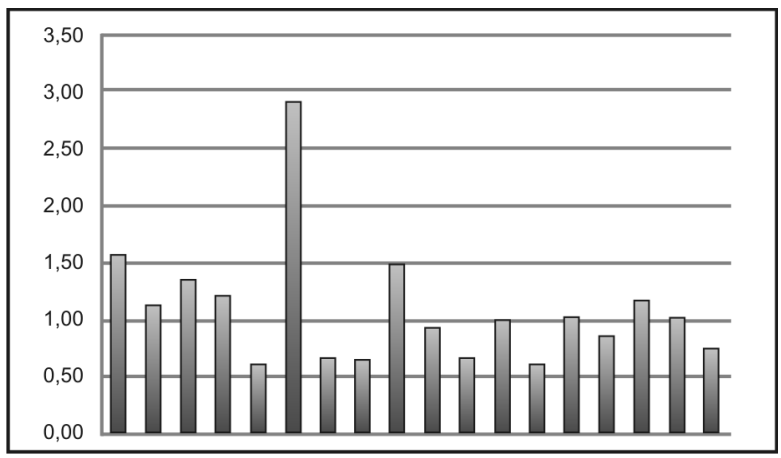

Gráfico 10: Média da produção docente (equivalentes a capítulos A) dos programas 4

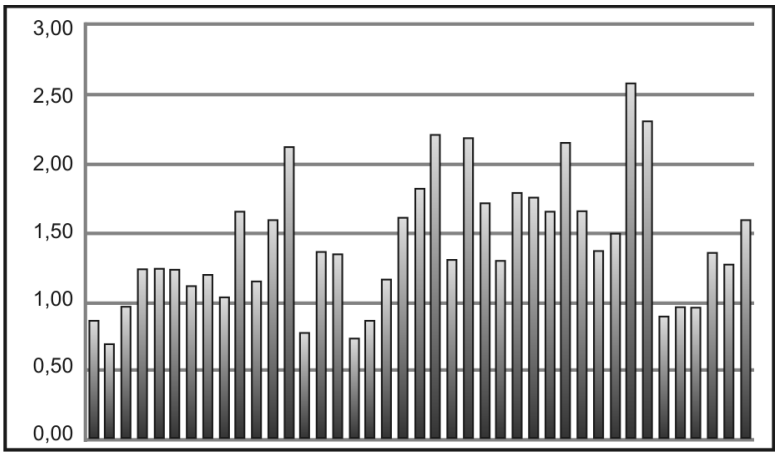

Gráfico 11: Média da produção docente (equivalentes a capítulos A) dos programas 5

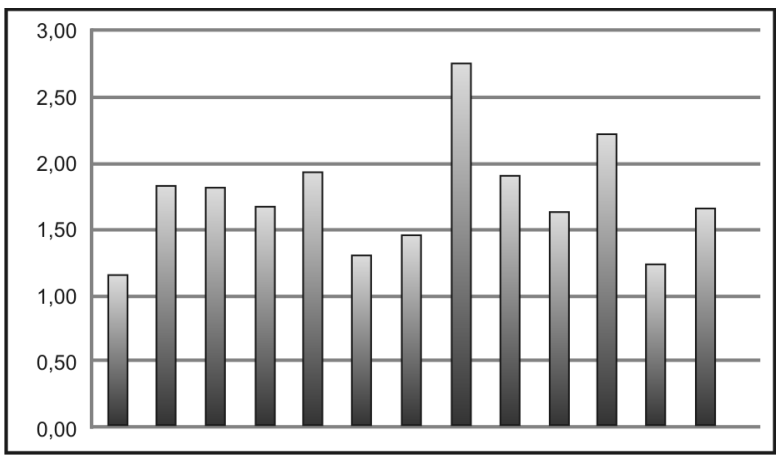

Gráfico 12: Média da produção docente (equivalentes a capítulos A) dos programas 6

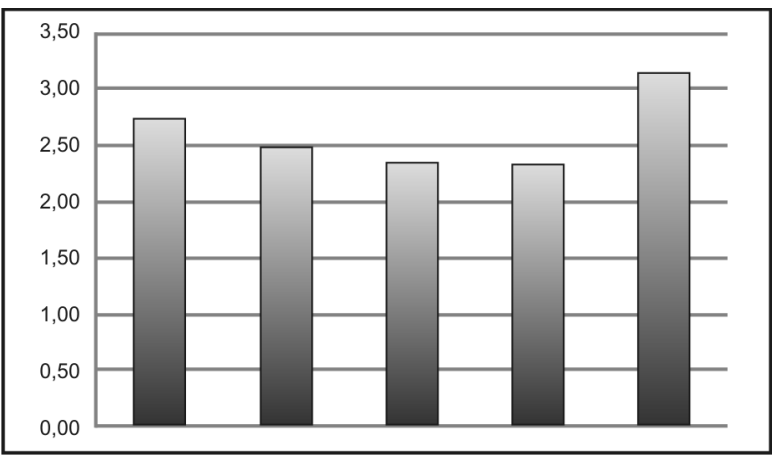

Em relação aos estratos mais elevados da avaliação (A e B para livros e Internacional e Nacional A e $\mathrm{B}$ para periódicos), os números de média de produção por docente por ano são ainda ligeiramente inferiores. À exceção dos programas 6 , nos demais conceitos essa produção total é inferior a dois produtos por ano (Gráficos 13 e 14). Considerada a produção apenas em periódicos, nem nos programas 6 esse número atinge a média de um produto por docente por ano (Gráfico 14). Entendemos que esses números não permitem concluir que há produtivismo na área induzido pela avaliação. Talvez nossa percepção de tal produtivismo tenha a ver com o crescimento da área em níveis de que ainda não nos demos conta: a centralidade na formação de pesquisadores realimenta o sistema, provocando sua rápida expansão e ampliando os números brutos da produção bibliográfica.

Gráfico 13: Mediana da média da produção docente em estratos mais elevados por conceito

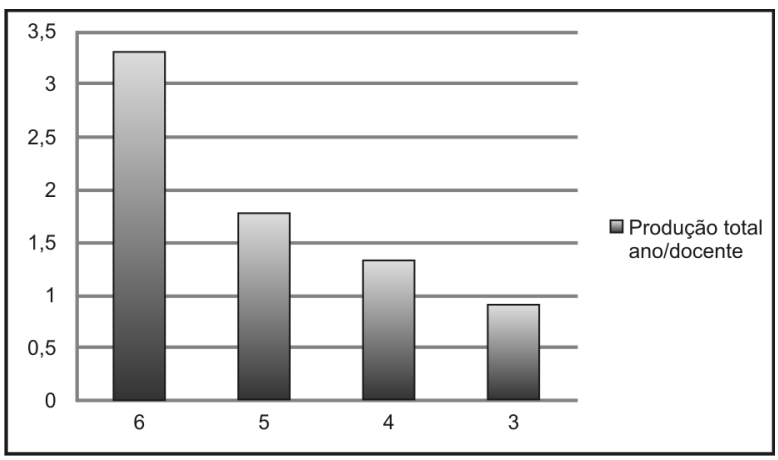


Gráfico 14: Mediana da média da produção docente em periódicos A e B por conceito

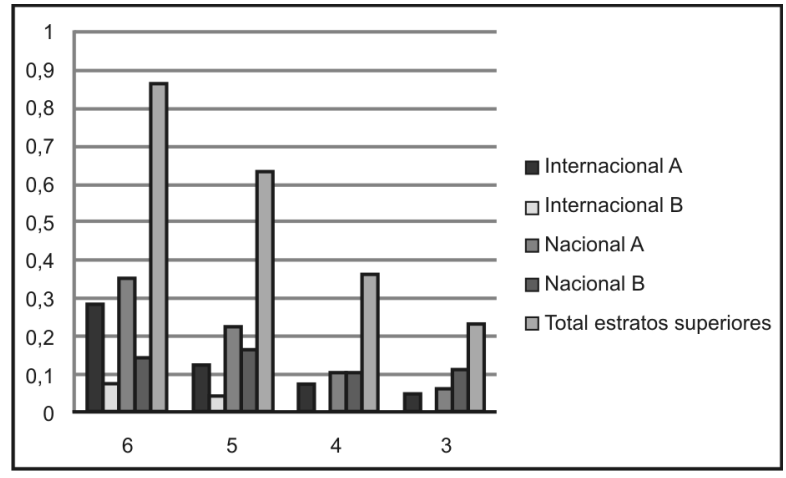

Gráfico 15: Mediana da média da produção docente em livros A e B por conceito

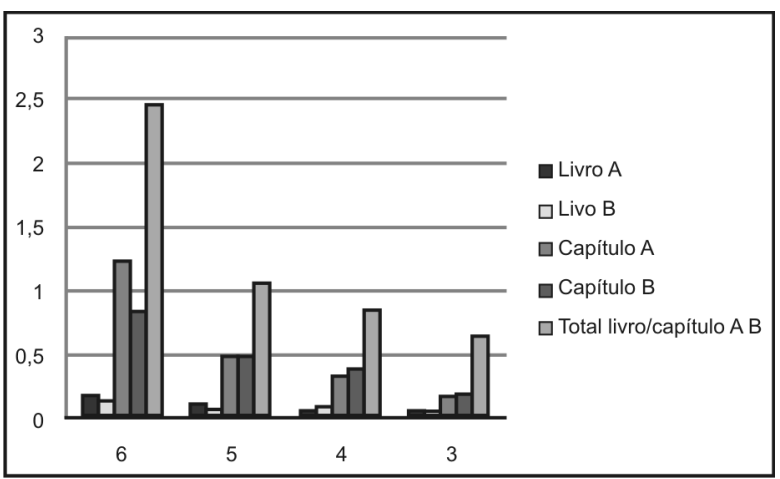

Preocupa-nos a nostalgia (restaurativa) de um tempo outro que subjaz ao discurso crítico do produtivismo. Para apoiar essa nostalgia, postula-se uma relação não sustentada entre quantidade e qualidade da produção: num tempo em que a produção era menor, era certamente, e por isso, melhor. Uma avaliação pouco sistemática da produção em educação hoje não parece deixar dúvidas de que ela é mais consistente do que o que se produzia nos anos de 1970 e 1980. As teses e dissertações recentes têm mais profundidade teórica, se comparadas com a média dos trabalhos defendidos nos anos 1970 e 1980. Nossos periódicos, além de mais numerosos, têm mais qualidade. A plêiade de livros que vemos hoje em eventos não é apenas quantitativamente maior, mas espelha uma produção própria dos pesquisadores da educação no Brasil em contraposição a uma ampla maioria de manuais e adaptações de literatura estrangeira que predominava nos anos de 1970.
Mas não é apenas porque julgamos essa nostalgia insustentável que nos esforçamos para desconstruí-la. Fazemo-lo porque julgamos que, em áreas como a educação, historicamente vinculada à extensão e que apenas mais recentemente vem construindo uma trajetória de produção científica consistente, essa nostalgia pode contribuir para a desmobilização e para um retrocesso nessa trajetória. Nossa preocupação tem-se intensificado recentemente, na medida em que se ampliam as demandas de diversas naturezas sobre a pós-graduação e sobre os seus docentes, especialmente das universidades públicas. Ainda que compreendamos e julguemos relevantes muitas das demandas de inserção social que vêm sendo lançadas aos programas, entendemos que nossa principal função é fazer bem aquilo que nos compete e para o que recebemos financiamento público: formar professores/pesquisadores e produzir conhecimento socializado. É pela competência com que temos desempenhado essas funções que somos respeitados pelas comunidades acadêmicas e socialmente, e esse respeito é nosso principal capital.

\section{Referências bibliográficas}

BOYM, Stevlana. The future of nostalgia. New York: Basic, 2001.

BRASIL - CAPES. Documento da área de educação. Brasília: CAPES, 2004. Disponível em: <http://www.capes.gov.br/capes/portal/ conteudo/2003_038_Doc_Area.pdf $>$. Acesso em: 3 jul. 2009.

BRASIL - CNPq. Desenvolvimento científico e formação de recursos humanos. Brasília: CNPq, 1983.

CAMERON, Catherine M.; GATEWOOD, John B. The authentic interior: questing Gemeinschaft in post-industrial society. Human Organization, v. 53, p. 21-32, 1994.

CÓRDOVA, Rogério de Andrade; GUSSO, Divonzir Arthur; LUNA, Sérgio Vasconcelos de. A pós-graduação na América Latina: o caso brasileiro. Brasília: UNESCO/CRESALC/MEC/ SESu/CAPES, 1986.

CUNHA, Luiz Antonio A. Ideias sobre avaliação. Boletim ANPEd, v. 7, n. 5, 6, p. 10-12, 1985.

FÁVERO, Osmar. Situação atual e tendências de reestruturação dos programas de pós-graduação em educação. Revista da Faculdade de Educação da USP, v. 22, n. 1, p. 51-88, jan./jun. 1996. 
Pós-graduação em educação: avaliação e perspectivas.

Revista de Educação Pública, v. 18, n. 37, p. 311-327, maio/ago. 2009.

HALL, Stuart. Da diáspora: identidades e mediações culturais. Belo Horizonte: Editora UFMG, 2003.

HORTA, José Silvério Baía. Prefácio. In: BIANCHETTI, Lucídio; MACHADO, Ana Maria Netto (Org.). A bússola do escrever: desafios e estratégias de teses e dissertações. São Paulo: Cortez; Florianópolis: UFSC, 2002.

.; MORAES, Maria Célia Marcondes de. O sistema CAPES de avaliação da pós-graduação: da área de educação à grande área de ciências humanas. Revista Brasileira de Educação, n. 30, p. 95-116, 2005.

KUENZER, Acácia; MORAES, Maria Célia Marcondes de. Temas e tramas na pós-graduação em educação. Educação e Sociedade, Campinas, v. 26, n. 93, p. 1.341-1.362, set./dez. 2005.

LACLAU, Ernesto. Power and representation. In: POSTER, Mark. Politics, theory and contemporary culture. New York: Columbia University Press, 1993.

; MOUFFE, Chantal. Hegemonia y estratégia socialista.

Buenos Aires: Fondo de Cultura Económica, 2004.

LOPES, Alice Casimiro. Discursos nas políticas de currículo. Currículo sem fronteiras, v. 6, n. 2, p. 33-52, jul./dez. 2006.

MOUFFE, Chantal. La paradoxa democrática. Barcelona: Gedisa, 2003.

SGUISSARDI, Valdemar. A avaliação defensiva no "modelo CAPES de avaliação". É possível conciliar avaliação educativa com processos de regulação e controle do Estado?. Perspectiva, v. 24, n. 1, p. 49-88, jan./jun. 2006.

VELHO, Gilberto. As ciências sociais nos últimos 20 anos: três perspectivas. Revista Brasileira de Ciências Sociais, v. 12, n. 35, p. 1-18, fev. 1997.

ELIZABETH MACEDO, doutora em educação pela Universidade Estadual de Campinas (UNICAMP), é professora do
Programa de Pós-Graduação em Educação da Universidade do Estado do Rio de Janeiro (UERJ) e coordenadora adjunta da área de educação na CAPES. Publicações recentes: em coautoria com LOPES, Alice Casimiro. Políticas de currículo em seus múltiplos contextos (São Paulo: Cortez, 2006) e Políticas de currículo no Brasil e em Portugal (Porto: Profedições, 2008). Como produto de convênio CAPES/FCT, organizou Políticas curriculares e dinâmicas educativas no Brasil e em Portugal (Porto: LIVPSIC, 2008). Pesquisa em andamento: "Currículo de ciências: uma abordagem cultural", financiado pelo Conselho Nacional de Desenvolvimento Científico e Tecnológico (CNPq) e pela Fundação de Amparo à Pesquisa do Estado do Rio de Janeiro (FAPERJ). E-mail: bethmacedo@pobox.com

CLARILZA PRADO DE SOUSA, doutora em Educação pela Pontifícia Universidade Católica da São Paulo, é professora do Programa de Pós-Graduação em Educação da mesma universidade e pesquisadora da Fundação Carlos Chagas, onde coordenada o Centro Internacional de Estudos em Representações Sociais e Subjetividade. É atualmente coordenadora da área de educação na CAPES. Publicações recentes: em coautoria com VILLAS-BOAS, Lúcia, Representações sociais sobre o trabalho docente (Aveiro: Universidade de Aveiro, 2009), Avaliação do rendimento escolar (Campinas: Papirus, 2008). Como produto de convênio entre diferentes universidades nacionais e europeias, é uma das organizadoras de Educação e trabalho: representações, competências e trajectórias (Aveiro: Universidade de Aveiro, 2007). Pesquisa em andamento: "Representações sociais de estudantes universitários (pedagogia e licenciatura) sobre o trabalho do professor", financiado pela Fundação Carlos Chagas e pela Fondation Maison des Sciences de l'Homme. E-mail: clarilza. prado@uol.com.br

Recebido em outubro de 2009

Aprovado em dezembro de 2009 
Elizabeth Macedo e

Clarilza Prado de Sousa

A pesquisa em educação no Brasil

$\mathrm{O}$ artigo debate a política de pós-graduação na área de educação, entendendo-a, a partir de E. Laclau e C. Mouffe, como politização incessante habitada pela indecidibilidade. Analisando textos recentes produzidos no processo de avaliação dos programas no âmbito 
da CAPES, considera possível compreender a formação provisória de consensos em torno de noções como a qualidade da pós-graduação entendida como significante vazio preenchido por meio de articulações hegemônicas. As autoras, após um breve quadro do sistema a partir dos resultados da avaliação do triênio 2004-2006, analisam dois aspectos que julgam centrais para o preenchimento da noção de qualidade: a articulação dos programas em torno de linhas de pesquisa e a produção/ disseminação do conhecimento. Em relação à articulação, defendem que as linhas podem ser entendidas como uma expressão da forma como os programas estão pensando o próprio campo da educação, num exercício que tem envolvido interdisciplinaridade e flexibilidade. Quanto à produção/disseminação do conhecimento, discordam de tese corrente de que a avaliação da pósgraduação tem levado a área a um produtivismo desenfreado, entendendo-a como nostalgia restauradora.

Palavras-chave: pós-graduação; avaliação; política educacional.

\section{Educational research in Brazil}

This paper discusses the graduate educational policy in the area of education, considering it, based on E.

Laclau and C. Mouffe, to be incessant politization imbued with undecidability. Analyzing recent texts produced in the process of evaluating programs in the sphere of CAPES, it considers it possible to understand the provisional formation of consensuses around notions like quality of graduate courses seen as an empty signifier filled by hegemonic articulations. The authors, after a brief summary of the system based on the results of the 2004-2006 three-year evaluation, analyze two aspects that they feel are crucial for filling in the notion of quality: the articulation of the programs around the research lines and the production/ dissemination of knowledge. As for the articulation, they maintain that the lines can be seen as an expression of the way in which the programs are thinking the actual field of education, in an exercise that has involved interdisciplinarity and flexibility. As for the production/dissemination of knowledge, they disagree with the current theory that the evaluation of graduate courses has led the area to an unrestrained productivism, seeing it as restorative nostalgia.

Key words: graduate educational policy; evaluation; educational policy.

\section{La pesquisa en la educación en \\ Brasil}

El artículo discute la política de postgrado en el área de la educación, entendiéndola a partir de E. Laclau y C. Mouffe, como la politización incesante habitada por lo que no se puede decir o explicar. Analizando textos recientes producidos en el proceso de evaluación de los programas en el ámbito de CAPES, considera posible comprender la formación provisoria de consensos alrededor de nociones como la cualidad del postgrado entendido como significante vacio, completado por medio de articulaciones hegemónicas. Las autoras, después de un breve cuadro del sistema, a partir de los resultados de la evaluación del trienio 2004-2006, analizan dos aspectos que consideran centrales para completar la noción de calidad: la articulación de los programas en torno a líneas de pesquisa y a la producción/diseminación del conocimiento. Con relación a la articulación, defienden que las líneas pueden ser entendidas como una expresión de la forma de como los programas están pensando en el propio campo de la educación, en un ejercicio que ha envuelto interdisciplinariedad y flexibilidad. En cuanto a la producción/ diseminación del conocimiento, dis- cuerdan de la tesis corriente de que la evaluación del postgrado ha llevado al área a un productivismo desenfrenado, entendiéndola como nostalgia restauradora.

Palabras claves: postgrado; evaluación; política educativa. 